\title{
17 The energy transition in Deventer
}

\author{
A Hanseatic approach
}

Ir. Almar Otten and Ron Sint Nicolaas

\section{Deventer: a culture of cooperation since Hanseatic times}

\section{A brief history of co-operation}

Deventer belongs to the five oldest cities of the Netherlands. In 768 the Frank missionary Lebuinus crossed the river IJssel to convert the Saxons to Christianity. He built a church at the high grounds at the crossing of the river IJssel and the Schipbeek. Deventer became an important trading place and was one of the first Dutch towns to join the Hanze, the economic cooperation between hundreds of towns surrounding the North and the East Sea.

Between the 11th and the 16th centuries, Deventer developed into a city of science and books. Desiderius Erasmus and Geert Grote, founder of the Modern Devotion, studied at the famous Latin School.

In the 18th century industry became the economic engine of the city. The Deventer company Noury van der Lande was one of the founding companies of the Akzo Nobel concern. The recently split off chemical division was therefor called Nouryon.

Nowadays Deventer, blessed with 100,000 inhabitants, has a mixed economic profile. There still are well-known industrial enterprises such as Auping (beds), Ardagh (tin cans), Byk-Cera (additives), Nefit-Bosch (heating systems) and Nouryon (research). Since 1950 however, knowledge industry became more important. Deventer is the home base of large and worldwide operating consultancy firms like Witteveen+Bos and Tauw. During the last ten years new IT- and New Technology firms emerged and grew rapidly on a fertile soil, formed during ages of innovation and co-operation.

\section{A brief history of sustainability}

Since 2007 Deventer has a local strategic plan on sustainable energy. The goal of the first plan was to be energy-neutral in 2030. Now, in 2019, this political goal is unchanged. The city council still aims at a fully sustainable energy system in 2030. There is however a growing awareness that $2030 \mathrm{might}$ be too optimistic. 
The financial means of the municipality have always been limited. Due to the lack of budget, we have always been focused on cooperation with other parties, such as industries, housing associations, schools, energy companies. In every partnership, the municipality had to be keen on managing the expectations about the governmental role.

From 2007 to 2015 the municipality basically adopted an opportunistic approach. That led for example to a project in which solar systems were placed on 53 government buildings, such as schools and sports halls. The municipality also took the lead in the spatial procedures to enable the construction of two wind turbines, partly owned by the local energy cooperation, at the entrance of the town.

In 2016 the first contours of the National Climate Agreement became clear. It was obvious that the Dutch municipalities would be assigned to take the lead in the local energy transition. At the same time, the Deventer municipality was approached by the two largest housing associations to talk about the future energy management in districts where they owned houses and where they had to decide about the replacement of the old heating system. Would they install new gas-based systems with a depreciation period of 12 years or was this the right time to choose a sustainable, non-fossil fuel dependent source of heat? They asked the municipality to develop a long-term energy strategy. The municipality, the housing associations and the energy network operator started a joint project, called 'Fossil Free and Affordable Housing'.

Zandweerd became the first district to radically start building a new heating system. In the present situation, all houses have individual gas boilers. These will be replaced a collective heat network. This network has two sources of heat. The first is the nearby sewage treatment plan. That delivers water with a temperature of about 40 degrees Celsius. The temperature of this water can be raised by electrical heat pumps to a maximum of 70 degrees, specifically dependent on the isolation state of the individual house of a block of houses.

\section{Towards a new strategy}

\section{Goals}

In May 2019 the Senate of the Dutch Parliament agreed upon the National Climate Agreement and the Climate Act. The national goals are formulated as follows:

i $49 \%$ reduction of $\mathrm{CO}_{2}$ emissions in 2030, based on the $\mathrm{CO}_{2}$ emissions in 1990;

ii $95 \% \mathrm{CO}_{2}$-emission in 2050;

iii A zero-emission production of electricity in 2050;

iv 1.5 million of 7 million houses heated free of fossil fuels in 2030 .

The Climate Act clearly appoints the municipality as director of the local energy transition. By law municipalities are assigned to develop the following plans: 
a a regional strategy as to produce a certain amount of sustainable energy (2020);

b a general plan for the transition of heat supply (2021);

c specific plans for transition of heat supply in districts, covering the whole town (2022).

From the national goals we can derive the following local goals for Deventer:

i in 2030 half of the energy we use should originate from sustainable sources;

ii in 2050 near to all of the energy we use should originate from sustainable sources;

iii in $203020 \%$ of all houses should be free of fossil fuels, that means 10,000 houses must be taken off the gas network in the next decade.

It is obvious that we need to change our strategy to achieve these goals. We cannot hold on to our basically reactive strategy of stimulating, facilitating, enhancing and connecting initiatives taken by others. The Climate Act tells us to take the lead, despite still having hardly any financial power. Moreover, from now on, major decisions must be made. The city council must take a stand in issues that will doubtlessly lead to major political and social controversies.

Although our role and position have changed, our new strategy will still be based on the co-operative way we worked during the last decade, based on mutual trust and understanding of needs and qualities.

\section{Two tasks}

The entire climate task exists of two major challenges of an entirely different order:

a the transition of heat supply;

b the production of sustainable (electrical) energy.

In directing the transition of heat supply we must deal with a broad range of questions of a technical, social, juridical or financial nature. What makes it even more complicated is that different parties are involved and that no party has the power, the assets and the authority to fulfil the task alone. Cooperation is a strict requirement;

The production of sustainable (electrical) energy is essentially a spatial issue: where do we want or don't want wind turbines or large solar systems? Apart from regulatory conditions, this task is governed by sentiments and political considerations.

Both tasks demand a different strategy. In the chapters below, we will describe our new strategy in the transition of heat supply and the production of sustainable (electrical) energy. 


\section{Strategy on the transition of heat supply}

\section{General approach}

The transition of heat supply in Deventer concerns 45,000 houses, more than $500,000 \mathrm{~m}^{2}$ offices and industrial buildings. The general approach is focused on districts, areas with a certain similarity in the type of buildings and energy infrastructure.

In 2017 the municipality and the four Deventer Housing Associations started the project 'Fossil Free and Affordable Homes.' Later also the network operators and the Water Board joined the project. The first focus of the project was to support the housing associations in deciding about the heat supply in the homes that were on the list for general maintenance and renovation. Now this project is the vehicle for the entire heat supply transition task.

Our strategy is based on answering the following questions:

- Where do we start?

- What source of heat do we choose?

- Who is responsible for the new heat infrastructure?

- Who is financing the transformation?

\section{Where do we start?}

Investment regimes of the partners involved determining our transformation planning. Therefore, it is of vital importance that partners are willing to share their financial plans in full transparency. That is only feasible if partners work in confidence.

From the start of the 'Fossil Free and Affordable Homes'-project, we have invested in gaining a mutual understanding of each other's position, motives and targets. When different worlds with different rules and regulations collide, an open mind and willingness to accept that, are crucial.

Investment regimes were combined with information such as the type and age of houses, the energy infrastructure, other development plans and social aspects. That lead to a subdivision of the town into 'logical' energy transformation districts.

There was no doubt that Zandweerd would be the district to start. In that district the following developments and opportunities came together:

a 150 new homes were newly developed by a commercial developer on the former site of a skating stadium. By law, these homes should be sustainably heated;

b 200 new homes were built by a housing association;

c 500 houses were on the list of heavy maintenance by another housing association; 
$\mathrm{d}$ the district is located close to the main sewage treatment plant and the river IJssel, which could serve as sources of heat;

e a collective heat system could in the future serve more than 5,000 homes in the same district.

\section{What source of heat do we choose?}

To select the best source of heat we must make three choices:

i Can we use a direct source of heat, such as geothermal or aquathermal, or is there no other possibility than to use electrical heat supply?

ii Do we use individual heat supply systems, such as small heat pumps, or do we prefer a collective heat supply system?

iii Can we supply a low-temperature heat or is a high-temperature heat required, mostly for older and less isolated homes?

Selecting the best system always asks for tailor-made solutions. In depends on many variables such as, age and construction of the houses, the presence of heat network nearby, the availability of a direct heat source and the risk of noise pollution caused by individual heat pumps.

In the project 'Fossil Free and Affordable Homes', we share knowledge and experience from different points of view. That enables us to make the right choice. In the process of decision making, we always must deal with the unknown future. Scientists and business are constantly working on improving existing techniques and developing new techniques. Together with our partners we keep a close eye on promising new techniques and are even willing to invest in the application of such. However, the possible emergence of new heating techniques, such as heating by means of hydrogen gas, is no excuse for a wait-and-see attitude.

We feel it our duty as local government to go ahead, make decisions and accept the risk of regretting some of our decisions.

\section{Who is responsible for the new heat infrastructure?}

In the Netherlands, the gas and electricity market are strictly regulated. The distribution network is semi-publicly owned, the supply of gas and electricity is a private market. At this moment the heat supply is not regulated. In Deventer, we have nine existing heat networks, all privately owned and based on fossil fuels, that serve about 10,000 homes.

It seems low hanging fruit to transform the fossil fuel-based networks into sustainable networks. In the present energy market, however, it is not financially profitable to invest in the sustainability of those networks. Network owners have limited willingness to close the gap between loss and profit.

In the district Zandweerd, we are planning to build a new heat network, based on heat from the sewage treatment plant. Here it must be decided who 
takes responsibility for the construction and the exploitation of the new network. We cannot to wait for the government to develop new legislation for the heat supply market. Pending this new legislation, the municipality has declared willing to take first responsibility in the realisation of heat networks. Later the municipality will decide about keeping that responsibility themselves or sell it on the market.

\section{Who is financing the transformation?}

The financial starting point of the transformation is the energy bill not to rise above trend. The energy transition is not supposed to become a burden on the shoulders of individual households. This financial demand severely limits the willingness of private companies to invest in new infrastructure. The municipality itself also lacks the financial means for significant investments. Therefor money must be found elsewhere.

In the short term, the next 2 or 3 years, we depend on the financial support of the national or provincial authorities for closing the gap between the commercial limits of the market and the limits of financially burdening the house owners.

For the long term, the municipalities of Deventer, Apeldoorn, Zutphen and Zwolle actively develop financial arrangements to accelerate the energy transition. This project called Transform aims at making residents and house owners an irresistibly good offer for an alternative energy and heat supply. Tailor-made, feasible and affordable.

An essential tool for Transform is the 'trex': the transition exploitation. The 'trex' contains all the investments and financial flows that are currently provided in the different districts, including the investments and operating costs required for the new energy and heat supply. Transform is, therefore, working on a financing scheme at the district level. National and European Investment banks and pension funds are interested in this and contribute their ideas. The aim of this scheme is that everyone can participate: owner-occupied and rented homes, shops, businesses, schools. All of them without the monthly energy bills increasing. Local projects of energy cooperatives or residents' initiatives are also included in the total area approach.

We are convinced that Transform or similar arrangements will be the financial vehicle for the realisation of the heat supply transition.

\section{Concise Deventer heat transition strategy}

Our goal is to transform the heat supply of 10,000 homes from natural gas to sustainable sources in 2030 and 45,000 homes in 2050. Our strategy can be summarised as follows:

a we divide the city into districts with similar energy infrastructure and types of houses; 
b the order of transformation is determined by the investment regimes of the partners involved;

c house owners are primarily responsible themselves for deciding on the applied techniques;

d information is shared to optimise the process of decision-making;

e the possible emergence of promising new heating techniques is no excuse for a wait-and-see-attitude;

$\mathrm{f}$ pending the new legislation regulating the heat supply market, the municipality is willing to take responsibility in the realisation of heat networks in the short term;

$\mathrm{g}$ the next two or three years we depend on the financial support of the national or provincial authorities for closing the gap between the willingness of the market and the financial strength of the house owners;

$\mathrm{h}$ for the long term we actively develop financial arrangements, based on the energy bill not to rise above trend.

\section{Strategy on the transition of production of electricity}

\section{Political debate}

Contrary to the heat supply transition, the sustainable production of electricity is not a technical challenge. It is essentially a political issue. It is all about balancing values. In general, the construction of large solar parks or huge wind turbines is regarded as a threat to our valuable and vulnerable landscape. In 2014 the city council had to decide about the construction of two 120-metre wind turbines at the entrance of the town, along the highway A1. It was a close finish. The council voted 18 against and 19 in favour of the wind turbines. The political debate was not limited to the city council. The discussion split parts of society.

For four years the subject of wind turbines and solar parks was banned from the political arena. The only thing that happened was an investigation of the appreciation of the wind turbines before and after the realisation. About 1500, randomly selected, inhabitants of Deventer were involved in the study. The results of the study showed that there was a very low appreciation during the period of preparation and decision making. A large majority would have voted against the wind turbines. One year after the placement of the wind turbines the appreciation appeared to have turned 180 degrees. A majority claimed to be proud of the wind turbines.

Our National Climate Agreement puts our local debate or non-debate in another perspective. Now the Climate Law forces us to explicitly make a statement about the sustainable production of electricity on Deventer territory.

Our strategy consists of the following steps:

- development of different scenarios based on energy numbers;

- show the spatial consequences of the scenarios;

- organise the process of realisation. 


\section{Energy numbers}

It is easy to formulate the goal that all electricity should originate from sustainable sources. Basic questions asked in a political debate are: how can we do it, how much do we need and what are the consequences? To give an impression of the measures required to reach our goals, we built a model that can be used for calculating different energy scenarios.

The first step is to determine what is the total amount of energy we must produce sustainably in 2030 of 2050 . The assumption that $50 \%$ of the future heating demand cannot be supplied by direct sources, leads to a total sustainable electricity demand of 3642 Terajoule. The model tells us that covering all roofs in town with solar panels provides only $22 \%$ of our total demand. We need to do more. But what? Wind turbines? The model shows that we need 135 large wind turbines to meet our demand. From a rapid appraisal, we know that a maximum of 22 wind turbines is feasible within the spatial regulations. So, what else can we do? Solar parks in rural areas? The model shows that we need over 1000 hectares of solar parks. Is that what we want?

Table 17.1 features a possible energy mix for Deventer. For our strategy, these kinds of numbers are of crucial importance. Without numbers the debate has no firm ground and discussions will end in the mud. Now anyone can use our model, change the underlying assumptions and create our own energy mix. This surely supports a good locale climate debate.

\section{Spatial consequences}

Figure 17.1 and Table 17.1 show the land use in the entire Deventer municipality. It also shows the locations where the placement of wind turbines is not obstructed by spatial regulations.

The energy mix described above is based on assuming that three additional wind turbines, possibly along the highway A1, is the maximum feasible. In that scenario, a total surface of nearly 800 hectares of solar parks in rural areas is needed to be fully sustainable. Thus, 800 hectares of agricultural land must be transformed into an ocean of glittering solar panels. It is obvious that not everyone will be enthusiastic.

Table 17.1 Possible energy mix for Deventer

\begin{tabular}{lcc}
\hline & Amount of energy $(\mathrm{Tj})$ & Surface (ha) \\
\hline Solar on roofs of homes & 254 & \\
Solar on roofs of companies & 140 & \\
Solar on roofs of farms & 79 & \\
Three wind turbines along highway A1 & 81 & 48 \\
Solar on ground urban areas & 163 & 65 \\
Solar on ground industrial areas & 221 & 0 \\
Solar on ground protected areas & 0 & 791 \\
Solar on ground other rural areas & 2704 & \\
Total & 3642 & \\
\hline
\end{tabular}




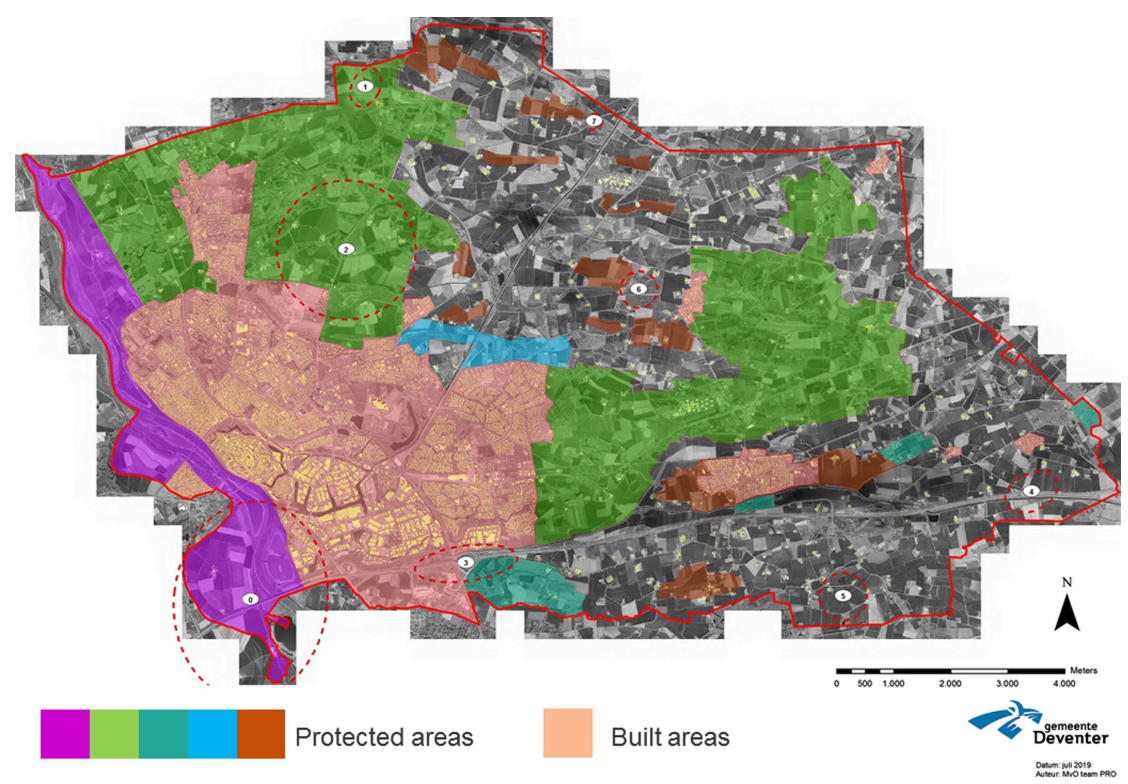

Figure 17.1 Land use in Deventer municipality.

Table 17.2 Land use in Deventer municipality

\begin{tabular}{lc}
\hline Usage & Surface in hectares \\
\hline Town and surrounding villages & 2.381 \\
Business and industrial areas & 645 \\
Protected rural areas (nature and landscape) & 5.074 \\
Other rural areas & 5.331 \\
Total & 13.432 \\
\hline
\end{tabular}

Ultimately the city council will decide what we are going to do.

\section{The process of realisation}

Independently of the local political debate, the Climate Law obliges us to make progress in the production of sustainable electricity. Besides, the exploitation of wind turbines and solar parks is a lucrative business. The municipality is frequently approached by companies that are interested to build wind turbines and solar parks. Pending the outcome of the political debate, we had to take the following temporary measures:

The city council established an action framework for companies that want to build a solar park. One of the most important regulations is that the initiator is primarily responsible for creating broad support in the area surrounding the proposed solar park. This support can be obtained by fitting the 
plans in the landscape or sharing the financial profit with the people affected by the plan.

For wind turbines, there is no action framework right now. That means that an initiator is fully responsible himself for the development of the plans and creating social and political support. From our experience with the two wind turbines that were built in 2014, we can estimate the total costs of preparation and decision making about several tons. Knowing that the outcome of the political process is highly uncertain, no initiator will start developing plans at his own cost and risk. If the city council agrees on adding three or more wind turbines to the existing two turbines, the municipality will have to take the risk for the preparation costs.

Besides, we have another urgent matter: the actual capacity of our electricity network is insufficient for the transition to locally produced electricity. Especially in rural and industrial areas, the network is already 'full'. Newly built solar systems on farms or factories can simply not be connected to the network. The municipality can only address the problem on a national level and join forces with the network operators.

\section{Conclusion}

Due to the lack of financial means, the municipality has always invested in cooperation with companies, housing associations, NGOs, inhabitants and other governmental authorities. We tried to create an atmosphere of transparency and understanding for motives, needs and ambitions of all parties involved. This context always forced the municipality to be clear about role, responsibility and means.

The National Climate Agreement puts our role from a different perspective. The municipality is the appointed director of the local energy transition. We see that our investments in building partnerships immediately pay-off. As in long gone Hanseatic times, we have confidence in the power of co-operation. In high spirit, we step towards a sustainable future.

\section{References}

Cooperation of Dutch Network Operators (2019). Basic Information about the Energy Infrastructure. The Hague: Cooperation of Dutch Network Operators.

Government of the Netherlands (2019). The Climate Act and the National Climate Agreement. The Hague: Government of the Netherlands.

Municipality of Deventer (2009). A sustainable Deventer: Towards a Climate Neutral Deventer in 2030. Deventer: Municipality of Deventer.

Municipality of Deventer (2011). Implementation Plan Sustainability: Towards a Sustainable Balance. Deventer: Municipality of Deventer.

Rotmans, J. (2017). Change of an Era: Our World in Transition. Amsterdam: Boom Publishers.

Vermeij, M. and K. van Koppen (2017). The Role of the municipality of Deventer in the Local Energy Transition. Wageningen: Wageningen University and Research. 